\title{
Real-time visualization of heterotrimeric $G$ protein Gq activation in living cells
}

\author{
Merel JW Adjobo-Hermans ${ }^{1,2}$, Joachim Goedhart ${ }^{1}$, Laura van Weeren ${ }^{1}$, Saskia Nijmeijer ${ }^{3}$, Erik MM Manders ${ }^{1}$, \\ Stefan Offermanns ${ }^{4}$ and Theodorus WJ Gadella Jr ${ }^{1 *}$
}

\begin{abstract}
Background: $\mathrm{Gq}$ is a heterotrimeric $\mathrm{G}$ protein that plays an important role in numerous physiological processes. To delineate the molecular mechanisms and kinetics of signalling through this protein, its activation should be measurable in single living cells. Recently, fluorescence resonance energy transfer (FRET) sensors have been developed for this purpose.

Results: In this paper, we describe the development of an improved FRET-based Gq activity sensor that consists of a yellow fluorescent protein (YFP)-tagged G $\gamma 2$ subunit and a Gaq subunit with an inserted monomeric Turquoise (mTurquoise), the best cyan fluorescent protein variant currently available. This sensor enabled us to determine, for the first time, the $k_{\text {on }}(2 / \mathrm{s})$ of $\mathrm{Gq}$ activation. In addition, we found that the guanine nucleotide exchange factor p63RhoGEF has a profound effect on the number of $\mathrm{Gq}$ proteins that become active upon stimulation of endogenous histamine $\mathrm{H} 1$ receptors. The sensor was also used to measure ligand-independent activation of the histamine $\mathrm{H} 1$ receptor (H1R) upon addition of a hypotonic stimulus.

Conclusions: Our observations reveal that the application of a truncated mTurquoise as donor and a YFP-tagged G $\gamma 2$ as acceptor in FRET-based Gq activity sensors substantially improves their dynamic range. This optimization enables the real-time single cell quantification of $\mathrm{Gq}$ signalling dynamics, the influence of accessory proteins and allows future drug screening applications by virtue of its sensitivity.
\end{abstract}

\section{Background}

Heterotrimeric $\mathrm{G}$ proteins are composed of $\mathrm{G} \alpha$ subunits and $G \beta \gamma$ dimers, and can be activated by G-proteincoupled receptors (GPCRs). Upon binding of an agonist, the receptor changes its conformation, and acts as a guanine nucleotide exchange factor (GEF). By inducing the exchange of guanine diphosphate (GDP) for guanine triphosphate (GTP) in the $G \alpha$ subunit, the $G$ protein becomes active [1]. G $\beta \gamma$ interacts with $G \alpha$ through two interfaces: the switch region and the region formed by the $\mathrm{N}$ terminus of the $\mathrm{G} \alpha$ subunit. Binding of GTP upon receptor activation disrupts the switch interface, which is thought to trigger the dissociation of $G \beta \gamma$ from $\mathrm{G} \alpha$ [2]. The family of $\mathrm{G} \alpha$ subunits consists of four classes; the subunits Gaq, Ga11, Ga14 and Ga16

\footnotetext{
* Correspondence: Th.W.J.Gadella@uva.n!

${ }^{1}$ Swammerdam Institute for Life Sciences, Section of Molecular Cytology, van Leeuwenhoek Centre for Advanced Microscopy, University of Amsterdam,

Science Park 904, 1098 XH, Amsterdam, The Netherlands

Full list of author information is available at the end of the article
}

belong to the Gq class. The principal target of the Gq class is phospholipase (PL)C $\beta$ [3]. Recently, RhoGEF proteins such as leukemia-associated Rho-guanine nucleotide exchange factor (LARG) and p63RhoGEF have been shown to directly interact with and to be regulated by Gaq, suggesting that they can link Gaqcoupled receptors to the activation of the small G protein RhoA [4-6].

Studying Gaq is important, because this protein is implicated in the development of myocardial hypertrophy after mechanical stress of the heart $[7,8]$. Because this is one of the triggers of cardiac failure, a leading cause of death in the western world, drugs to inhibit Gaq are much in demand [9]. Proteins belonging to the Gq class are also involved in the modulation of synaptic transmission $[10,11]$, cell growth, platelet aggregation [12], glucose secretion, actin cytoskeletal rearrangements, hematopoietic cell differentiation, leukocyte activation and contraction of smooth muscle, emphasizing their importance in human physiology [13].

\section{Biomed Central}


Recently, several fluorescence resonance energy transfer (FRET) sensors have been developed to monitor the activation state of specific heterotrimeric $G$ proteins in living cells upon GPCR activation [14-21]. In this paper, we report on the development of a highly sensitive sensor based on functional mTurquoise-tagged Gaq and yellow fluorescent protein (YFP)-tagged G $\gamma 2$, which allows for monitoring of the location and $G$ protein activation state of $\mathrm{Gq}$ in living cells and of the kinetics of the process. In addition, we describe the effects of ligand-dependent and ligand-independent stimulation of endogenous and overexpressed receptors, while concurrently monitoring the influence of effectors on the behaviour of the sensor. We opted for dual emission ratiometric FRET measurements supplemented with FRET-fluorescence lifetime imaging microscopy (FLIM) measurements to monitor the kinetics of $\mathrm{Gq}$ activation and FRET efficiencies, respectively.

\section{Results}

\section{Construction of a Gq FRET sensor}

To further our understanding of the kinetics of Gq signalling in living cells, we prepared visible fluorescent protein (VFP)-tagged human Gaq subunits. Because neither $\mathrm{N}$ - nor C-terminal fusions of Gas to VFP retained functionality [22,23], we opted for insertion of the fluorescent protein. The VFP insertion site was based on a Gaq tagged with hemagglutinin (HA) in the $\alpha$-helical domain (residues 125-ENPYVD-130 replaced by DVPDYA $[24,25]$ ) and on green fluorescent protein tagged Gaq (Gaq-GFP), as described previously [26]. Monomeric (by applying the A206K mutation [27]) YFP (mYFP) was inserted into the $\alpha \mathrm{B}-\alpha \mathrm{C}$ loop of the Gaq subunit (see Methods section for more details). Upon transient expression, the protein was found at the plasma membrane, as judged from the fluorescence pattern seen in HeLa cells (Figure 1A). Fluorescence was also, to variable extents, detected in the cytoplasm and occasionally in the nucleus. In various other cell lines (Madin-Darby canine kidney (MDCK), N1E-115 neuroblastoma and HEK293) a similar pattern was seen (see Additional file 1A-C). The localization pattern of GaqGFP has been thoroughly described by Berlot and colleagues [26], and is comparable with the Gaq-mYFP variant reported here.

FRET, which is a distance- and conformation-dependent phenomenon, is very useful for the study of dynamic protein interactions in living cells [28]. To measure FRET, various techniques can be used. To investigate the kinetics of the interaction between Gaq and the G $\beta \gamma$ dimer, FRET ratio imaging with a cyan fluorescent protein (CFP)-YFP pair was the method chosen. Ratiometric imaging is an intensity-based technique to analyze FRET, which involves measurement of the ratio between donor and acceptor fluorescence intensity after induction of signal transduction [29]. Recently, we reported a novel bright CFP variant, monomeric Turquoise $(\mathrm{mTq})$, which has excellent properties for use in FRET imaging. This fluorescent protein is a monomeric CFP variant that is twice as bright as enhanced (E)CFP, is more photostable, displays an improved signal:noise ratio for ratiometric FRET measurements, has a long fluorescent lifetime, and decays mono-exponentially [30]. Therefore, we replaced the mYFP with $\mathrm{mTq}$ in the Gaq-mYFP construct to use it as a donor in FRET studies.

Since $\mathrm{mTq}$ is inserted and the $\mathrm{N}$ and $\mathrm{C}$ termini of $\mathrm{mTq}$ are on the same side of the $\beta$-barrel, we reasoned that a C-terminal deletion of six amino acids (mTq $\Delta 6$, yielding a fluorescent $\mathrm{mTq}$ as in yellow cameleon [31]) would effectively bend the $\mathrm{mTq}$ moiety in Gaq, thereby forcing the $\mathrm{mTq}$ fluorophore (and its dipole moment) in another orientation. This could have a profound effect on the FRET efficiency (via the $\kappa^{2}$ orientation factor, [28]). Importantly, this variant was also found at the plasma membrane in HeLa cells, similar to Gaq-mYFP (see Additional file 1D).

We chose to tag the $\mathrm{N}$ terminus of G $\gamma 2$ with YFP, to effectively label the G $\beta \gamma$ dimer with an acceptor, as this fusion has previously been shown to retain functionality [32].

\section{Functionality of the $\mathrm{Gq}$ sensor}

The functionality of the fluorescent Gaq proteins (GoqmYFP and Gaq-mTq $\Delta 6$ ) was tested in a mouse embryonic fibroblast (MEF) cell line prepared from Gaq/11deficient mice [33]. This cell line $\left(\mathrm{MEFq} / 11^{-/-}\right)$and a MEF cell line prepared from wild-type mice express the bradykinin (BK) type 2 receptor that couples to Gaq [34]. As expected, addition of BK $(1 \mu \mathrm{mol} / \mathrm{l})$ led to an increase in cytosolic calcium in the wild-type MEF cell line (Figure $1 \mathrm{~B}$ ), but not in the $\mathrm{MEFq} / 11^{-/-}$cell line (Figure 1C). Expression of wild-type Gaq (Figure 1D), GaqmYFP (Figure 1E) or Gaq-mTq $\Delta 6$ (Figure 1F) in MEFq/ $11^{-/}$cells caused an increase in cytosolic calcium upon addition of BK. These results indicate that Gaq-mYFP and Gaq- mTq $\Delta 6$ can substitute for the wild-type Gaq in living cells devoid of endogenous Gaq/11 proteins. Using western blot analysis (see Additional file 2), we compared the expression level of endogenous Gaq/11 in MEF cells from wild-type mice with that of Gaq-mYFP transduced into MEFq/11 $1^{-/-}$. Gaq-mYFP in MEFq/11 ${ }^{-/-}$ was clearly less abundant than Gaq/11 in wild-type MEF cells, indicating that the observed calcium responses are not simply due to overexpression.

Correct localization of the heterotrimer requires cotransfection of the three subunits, as described previously [35]. To examine whether Gaq-mTq forms a 

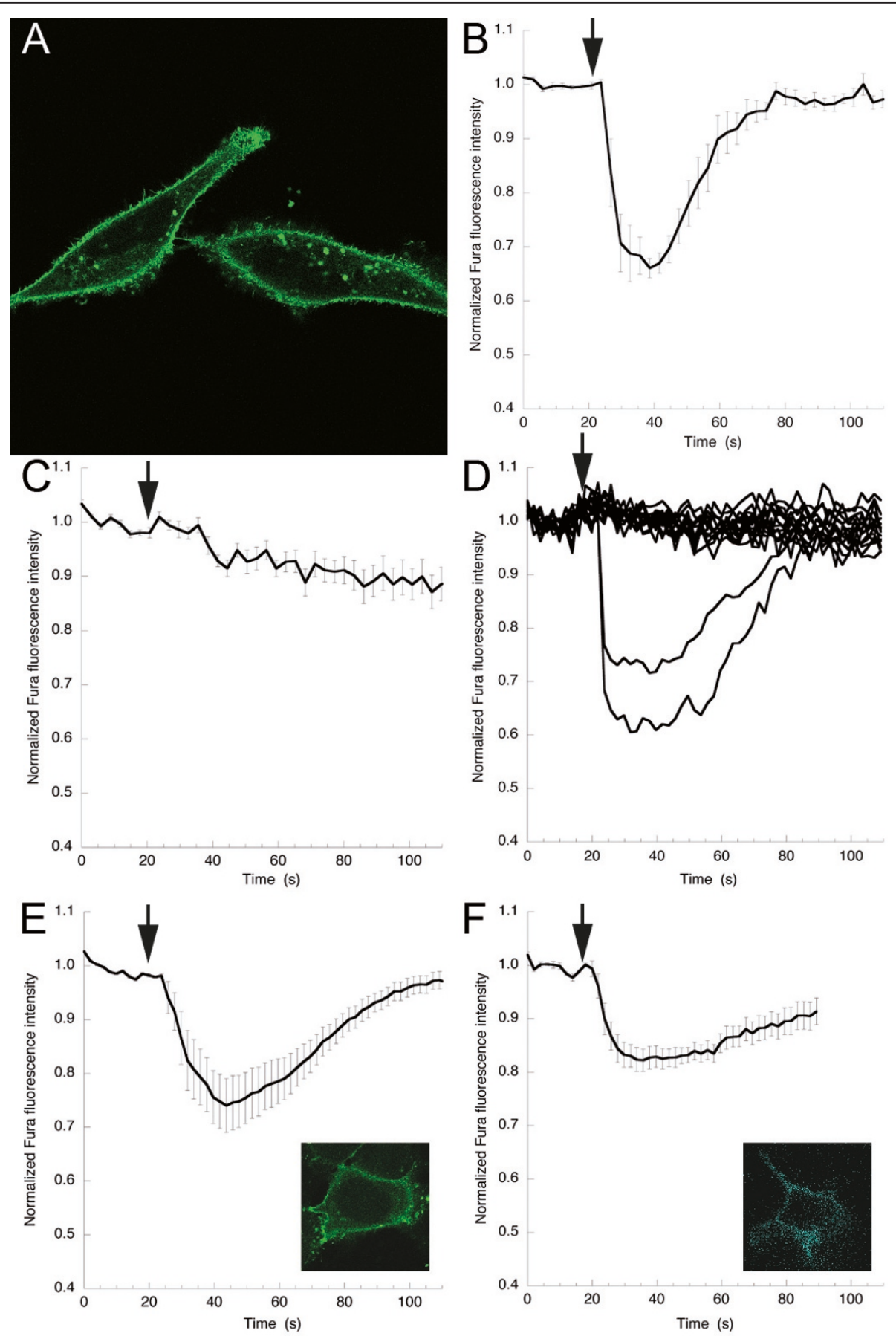

Figure $1 \mathrm{G} \alpha q$-visible fluorescent protein (VFP) is functional. (A) HeLa cells expressing Gaq tagged with monomeric yellow fluorescent protein (Gaq-mYFP). (B) Mouse embryonic fibroblasts (MEFs) derived from wild-type mice showed an increase in $\left[\mathrm{Ca}^{2+}\right]_{i}$ upon addition (arrow) of bradykinin (BK) (1 $\mu \mathrm{mol} / / \mathrm{l}, \mathrm{n}=6$. Error bars depict SE). (C) MEFs derived from $\mathrm{G} \alpha \mathrm{q} / 11$-deficient mice $\left(\mathrm{MEFq} / 11^{-/}\right)$did not display increased $\left[\mathrm{Ca}^{2}\right.$ $\left.{ }^{+}\right]_{i}$ upon addition of BK $(n=9)$. (D) Expression of wild-type G $\alpha q$ in $M E F q / 11^{-1-}$ caused an increase in cytosolic calcium upon addition of BK $(n=$ 2). Most cells did not express the re-introduced wild-type (untagged) Gaq and did not show a decrease in Fura Red intensity upon addition of

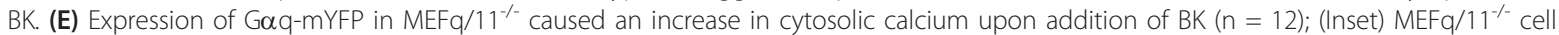

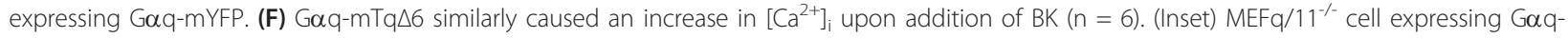
mTq $\Delta 6$. 
heterotrimer with the YFP-tagged G $\beta \gamma$ dimer, steadystate FRET efficiencies were measured in cells coexpressing Gaq-mTq and YFP-G $\gamma 2$. The truncated version, Gaq-mTq $\Delta 6$, displayed a higher basal FRET level (FRET efficiency 26\%; see also Figure 6) in the presence of YFP-G $\gamma 2$, compared with the non-truncated form (FRET efficiency 18\%; data not shown) and was therefore used in $\mathrm{Gq}$ activation measurements.

\section{Dynamic range of the $\mathrm{Gq}$ sensor}

During the course of our studies, Jensen et al. [19] published data on $\mathrm{Gq}$ activation using FRET ratio imaging with Gaq-ECFP and EYFP-G $\beta 1$. We compared the expression of Gaq-ECFP with that of Gaq-mTq $\Delta 6$ by transfecting cells with similar quantities of DNA. Cells expressing G $\alpha q-\mathrm{mTq} \Delta 6$ were readily visible, whereas cells expressing Gaq-ECFP were substantially less fluorescent (see Additional file 3).

To determine the dynamic range of our Gq activity sensor, we overexpressed the histamine $\mathrm{H} 1$ receptor (H1R) in HeLa cells, and compared the amplitude of the ratio change of our and the previously described sensor [19] under identical conditions (Figure 2A,B). We examined the expression of H1R and Gaq-mTq $\Delta 6$ under these conditions. Binding studies with a radiolabeled ligand revealed $710 \mathrm{fmol} / \mathrm{mg}$ binding sites, which is about fivefold higher than that of wild-type levels (150 $\mathrm{fmol} / \mathrm{mg}$ for mock-transfected HeLa cells). Western blotting (see Additional file 2) indicated that Gaq$\mathrm{mTq} \Delta 6$ was expressed at a level equal to the endogenous Gaq protein.

Addition of histamine caused intensity changes with much larger amplitudes (about twice as high) in our Gq sensor. The intensity traces unequivocally showed that, upon stimulation, the intensity of the donor ( $\mathrm{mTq}$ ) increased, whereas the sensitized emission of the acceptor (YFP) decreased (Figure 2A, inset), indicating a loss of FRET and reflecting an increase in distance between the $\alpha \mathrm{B}-\alpha \mathrm{C}$ loop of Gaq and the $\mathrm{N}$ terminus of $\mathrm{G} \gamma 2$, or a change in orientation. These clear, reciprocal changes in CFP and YFP intensities were not seen for the other sensor under identical circumstances (Figure 2B, inset). The results confirm the improved fluorescence properties of mTurquoise [30] and the benefits of deleting the six C-terminal amino acids of this tag.

Addition of the H1R inverse agonist mepyramine [36-38] readily caused deactivation (Figure 2; see Additional file 4). Under H1R overexpression conditions and in the continued presence of histamine in the medium, activation of $\mathrm{Gq}$ remained unaltered for at least $8 \mathrm{~min}$ utes (see Additional file 5). Similar changes were seen upon overexpression of the BK receptor type 2 (data not shown).
To ascertain the effect of using YFP-G $\gamma 2$ as acceptor instead of EYFP-G $\beta 1$, we determined the FRET change in cells coexpressing Gaq-mTq $\Delta 6$ and EYFP-G $\beta 1$ (Figure $2 \mathrm{C}$ ). Using EYFP-G $\beta 1$ as acceptor clearly diminished the amplitude of the response, indicating that the use of YFP-G $\gamma 2$ as an acceptor increases the sensitivity of the sensor. When Gaq-ECFP was used together with the acceptor YFP-G $\gamma 2$, a more robust FRET change was seen (compare Figure 2D with 2B). In summary, these data show that the combination of Gaq-mTq $\Delta 6$ and YFP-G $\gamma 2$ significantly improve the response of the $\mathrm{Gq}$ activity sensor.

To investigate the sensitivity of our sensor (Gaq$\mathrm{mTq} \Delta 6 /$ YFP-G $\gamma 2$ ), we overexpressed H1R and tested the response of the sensor to a range of agonist concentrations (Figure 3). Interestingly, a transient FRET change was seen upon stimulation with $0.1 \mu \mathrm{mol} / \mathrm{l}$ histamine, whereas its duration was prolonged upon addition of higher amounts of histamine. It seems that the amount of active Gq accumulates progressively every time the total concentration of histamine is increased, and that concomitantly, active $\mathrm{Gq}$ is desensitized less efficiently at each new histamine addition.

\section{Kinetics of $\mathrm{Gq}$ activation}

An important parameter describing the Gq activation kinetics is its activation rate $\left(\mathrm{k}_{\mathrm{on}}\right)$ upon receptor activation. To date, no conclusive data has been produced to quantify this kinetic parameter. By monitoring the FRET change kinetics of the FRET pair (Gaq- mTq $\Delta 6$ and YFP-G $\gamma 2$ ) upon addition of histamine, we were able to determine the activation kinetics of the heterotrimer. Activation of $\mathrm{Gq}$ was too fast to be measured by our widefield set-up (which used sequential CFP/YFP acquisition), therefore the experiments were repeated using a laser-scanning microscope with a resonant scanner. With this, it was possible to perform ratio imaging of FRET with a frame rate of around 15 frames/s, which provided sufficient temporal resolution to measure the kinetics of Gaq activation by $\mathrm{H} 1$ receptors (Figure 4A). The activation kinetics was appropriately fitted using a monoexponential curve, yielding a half-time for activation of $350 \mathrm{~ms}$ (Figure $4 \mathrm{~B}$ ), implying that $\mathrm{k}_{\text {on }}=2 / \mathrm{s}$.

\section{Influence of accessory proteins on the activation state of Gq}

Besides studying activation kinetics under receptor overexpression conditions, we were interested in obtaining data in the absence of overexpressed receptors. Stimulation of the endogenous [39] histamine receptor type 1 (H1R) in HeLa cells by addition of histamine also led to a measurable FRET decrease (Figure 5A), but with markedly different kinetics. Because $G \alpha$ subunits cycle between their inactive (GDP-bound) and active (GTP- 

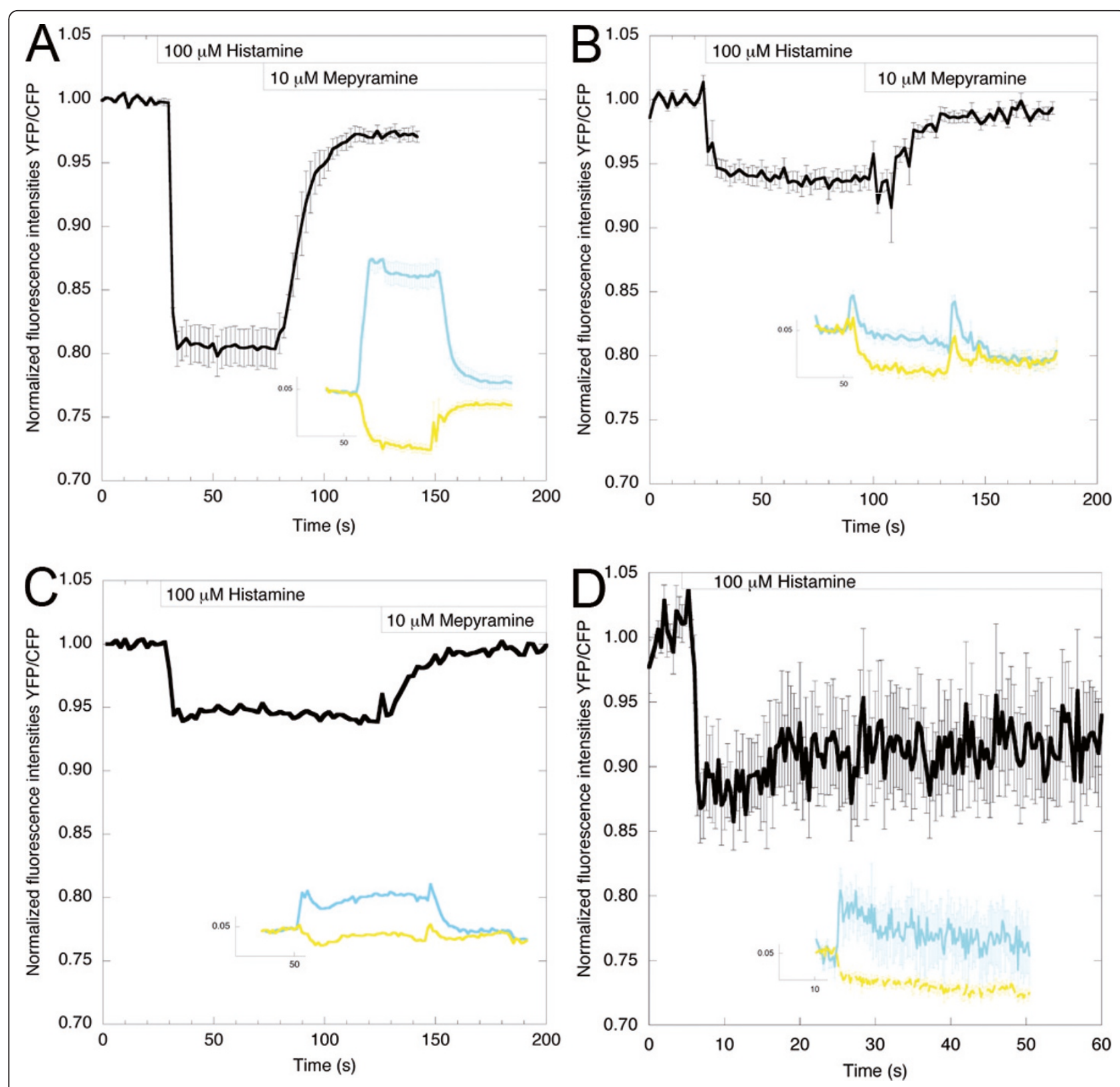

Figure 2 Dynamic range of Gq sensors. (A) The fluorescence resonance energy transfer (FRET) ratio change (yellow fluorescent protein: monomeric Turquoise (YFP:mTq)) upon addition of histamine $(100 \mu \mathrm{mol} / \mathrm{l})$ in HeLa cells coexpressing G $\alpha q-\mathrm{mTq} \Delta 6, \mathrm{G} \beta 1$, YFP-G $\gamma 2$ and the histamine $\mathrm{H} 1$ receptor ( $\mathrm{H} 1 \mathrm{R})$ (Inset) the $\mathrm{mTq}$ and YFP intensity traces from which the ratio was derived ( $\mathrm{n}=14$; error bars depict SE). Addition of the H1R inverse agonist mepyramine $(10 \mu \mathrm{mol} / \mathrm{l})$ reversed the ratio change induced by histamine. (B) The FRET ratio change (YFP:CFP) upon addition of histamine $(100 \mu \mathrm{mol} / \mathrm{l})$ in HeLa cells coexpressing Gaq-enhanced (E)CFP, EYFP-Gß 1, G $\gamma 2$ and H1R. (Inset) the CFP and YFP intensity traces from which the YFP:CFP ratio was derived ( $n=17$; error bars depict SE). (C) Representative trace of the FRET ratio change (YFP:mTq) upon

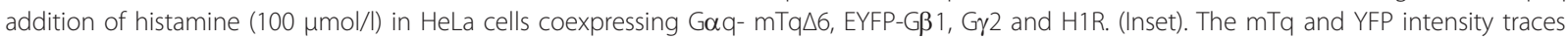
from which the ratio was derived. (D) The FRET ratio change (YFP:CFP) upon addition of histamine (100 $\mu$ mol/I) in HeLa cells coexpressing G $\alpha q-$ ECFP, G $\beta 1$, YFP-G $\gamma 2$ and H1R. (Inset) the CFP and YFP intensity traces from which the ratio was derived ( $n=5$; error bars depict SE).

bound) states, the duration of the active state is limited by its intrinsic GTP hydrolysis and GTP-ase activating protein (GAP) activity executed by accessory proteins. Remarkably, even in the continuous presence of agonist, the activation state of Gq is partially desensitized (Figure
5A), contrary to reports for Gai [16] and Gas (albeit in the presence of overexpressed receptors) [17]. Clearly, under H1R overexpression conditions (Figure 2A; Figure $5 \mathrm{~B}$; see Additional file 5), the activation state of $\mathrm{Gq}$ is prolonged. Gaq can be stimulated to hydrolyze its 

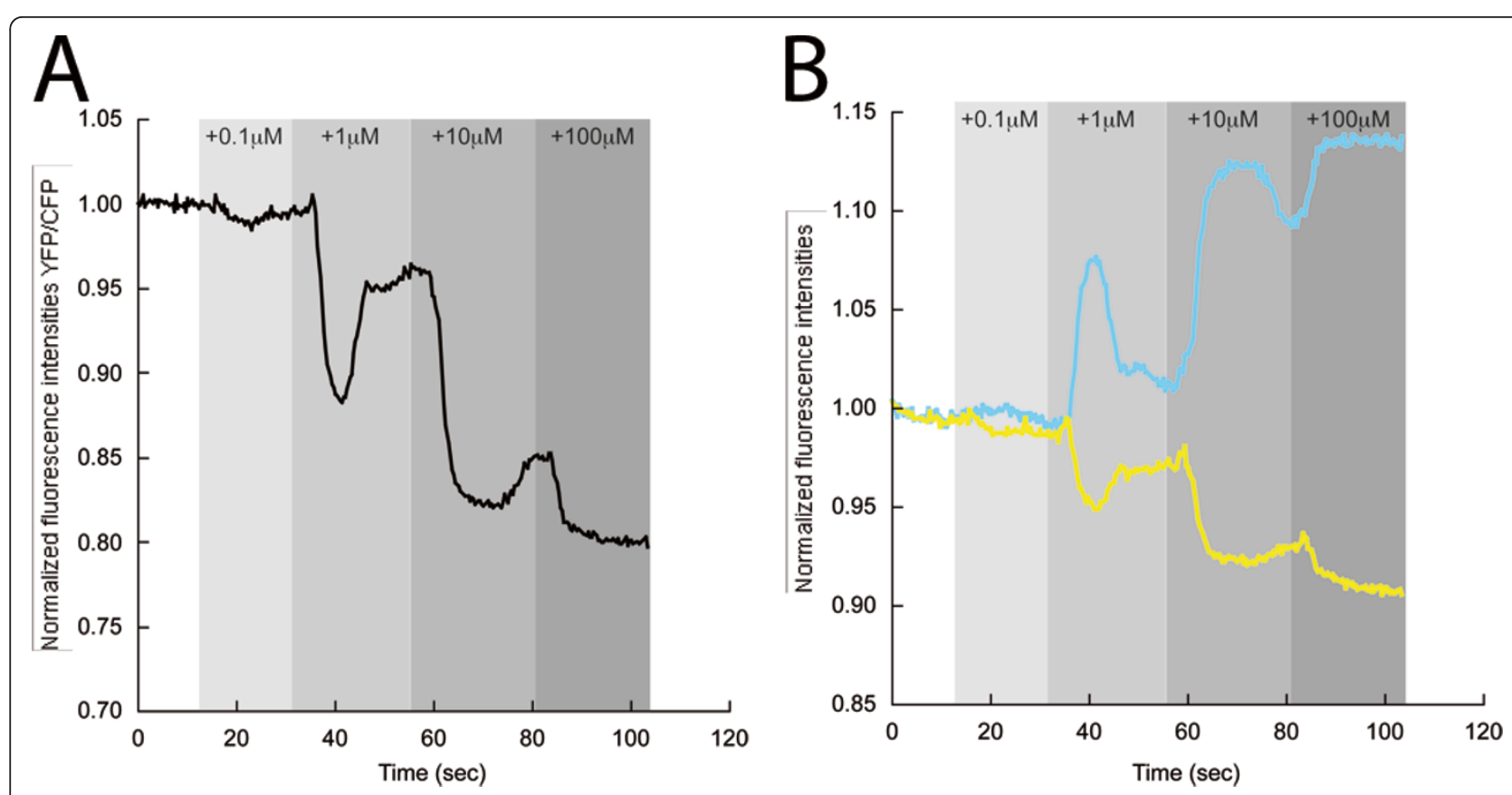

Figure 3 Dose-response curve. (A) Representative trace depicting the fluorescence resonance energy transfer (FRET) ratio changes (yellow fluorescent protein:monomeric Turquoise (YFP:mTq)) upon addition of increasing amounts of histamine (gray bars) in HeLa cells expressing Gaq$\mathrm{mTq} \Delta 6, \mathrm{G} \beta 1$, YFP-G $\gamma 2$ and the histamine $\mathrm{H1}$ receptor (H1R). (B) The $\mathrm{mTq}$ and YFP intensity traces from which the ratio was derived.

bound GTP by both regulators of G-protein signalling (RGS) proteins and phospholipase (PL)C $\beta$ isozymes $[40,41]$. To test the role of RGS proteins in desensitization of active Gq, an RGS-insensitive Gaq-mTq $\Delta 6$ was constructed by mutating G188 in switch I into S188. This mutation has been shown to inhibit binding of RGS proteins to Gaq ([42] and references therein), while leaving the intrinsic rate of GTP hydrolysis unchanged. FRET measurements using G $\alpha$ q-mTq $\Delta 6-G 188 S$ and YFP-G $\gamma 2$ show that the onset of Gq activation is slower. Desensitization also seems to be compromised, albeit not completely absent (see Additional file 6).

Next, we studied the influence of the recently described effector of Gq, p63RhoGEF $[5,6,43]$, on the activation state of Gq. Strikingly, coexpression of p63RhoGEF again caused an increase in the observed ratio changes between Gaq-mTq $\Delta 6$ and YFP-G 2 upon addition of histamine (Figure $5 \mathrm{C}$ ). The decrease in FRET readily returned to baseline upon addition of mepyramine (see Additional file 7). Importantly, the Gaq-interaction mutant p63RhoGEF-L475A [43] did not induce such an increase (see Additional file 8).

The prolonged FRET response with stimulation in the presence of p63RhoGEF or overexpressed H1R enabled us to apply the more quantitative FLIM technique to measure FRET levels. With FLIM, the excited state lifetime of the donor fluorophores is determined. In the case of FRET, the excited state duration is shortened because of transfer of energy to the acceptor [44]. Because fluorescence lifetimes do not depend on local excitation intensity or fluorophore concentration, and are largely unaffected by moderate levels of photobleaching of the fluorophores, FLIM is a very robust method to quantify FRET in living cells [29]. In the case of frequency-domain FLIM, two lifetimes can be measured, that is, the phase lifetime and the modulation lifetime, which both decrease in FRET.

The FLIM data revealed a reduction of the mTurquoise modulation lifetime (data not shown) and phase lifetime from 3.4 ns (donor only) to $2.5 \mathrm{~ns}$ in the presence of its acceptor YFP-G $\gamma 2$ (Figure 6). These lifetimes correspond to a FRET efficiency of $26 \%$. In the presence of H1R, similar FRET efficiencies were seen in resting cells, but upon addition of histamine, the donor lifetime increased. Similar increases were found by stimulating cells coexpressing p63RhoGEF with the Gq FRET sensor. These results unequivocally showed a decrease in FRET in the Gq sensor upon GPCR stimulation (Figure 6; see Additional file 9), corroborating the ratiometric data.

\section{Ligand-independent activation of $\mathrm{H} 1 \mathrm{R}$ activates $\mathrm{Gq}$}

Recently, Mederos y Schnitzler et al. [45] reported that certain GPCRs function as sensors of membrane stretch, with the $\mathrm{H} 1$ receptor being particularly mechanosensitive compared with AT1R, M5R and V1AR. Membrane 


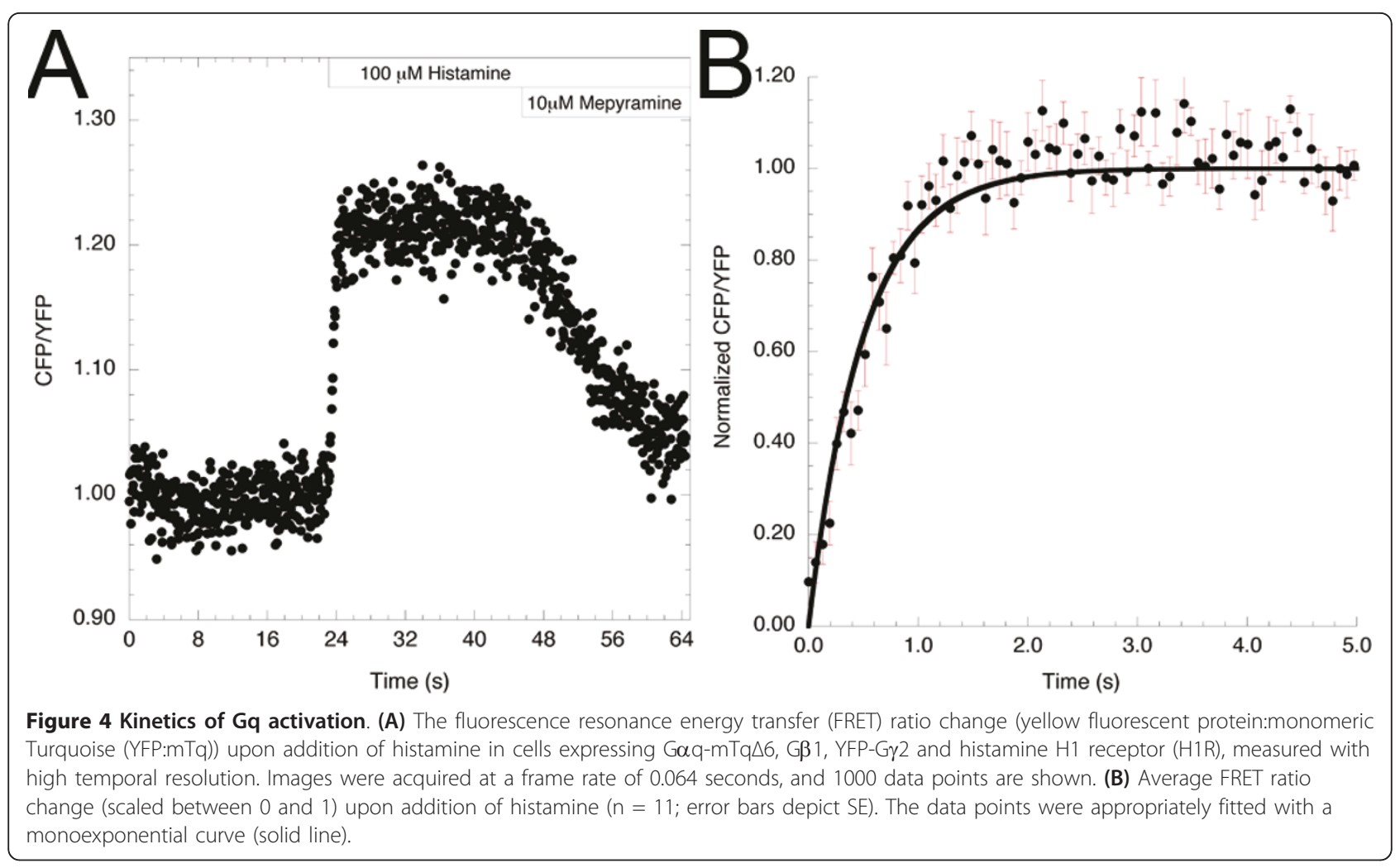

stretch can be induced by the application of a hypotonic stimulus (hypotonic cell swelling). First, we examined whether hypotonic stimulation of endogenous H1 receptors of HeLa cells could induce Gq activation, and found that it was not sufficient to produce a measurable $\mathrm{Gq}$ activation, as a ratio change was not seen (Figure
7A). Importantly, the same cells were capable of responding to histamine (Figure 7A).

Next, we examined whether overexpression of $\mathrm{H} 1$ receptors could trigger $\mathrm{Gq}$ activation upon application of a hypotonic stimulus. A clear FRET decrease was seen in these cells (Figure 7B), indicating Gq activation.

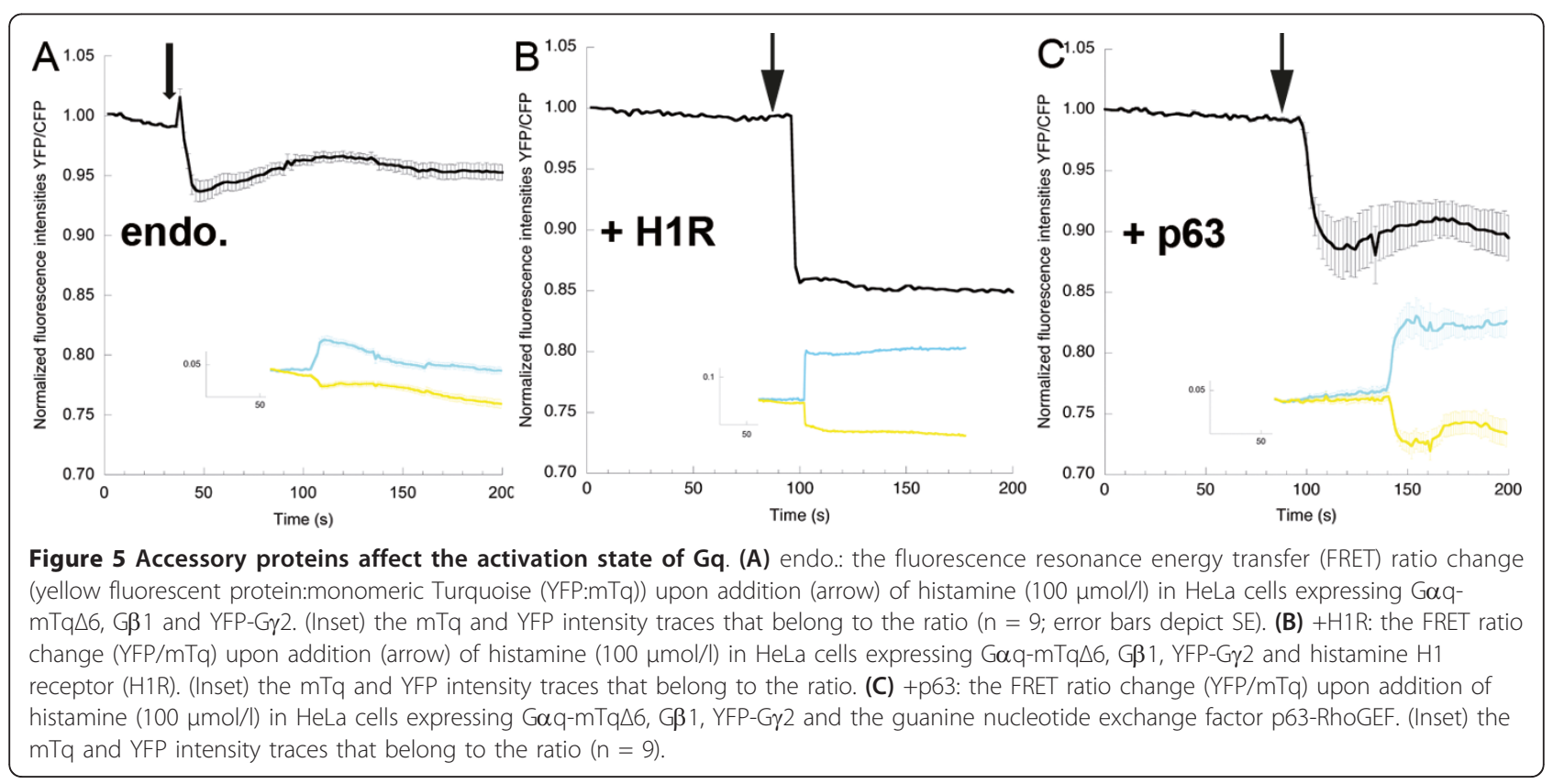




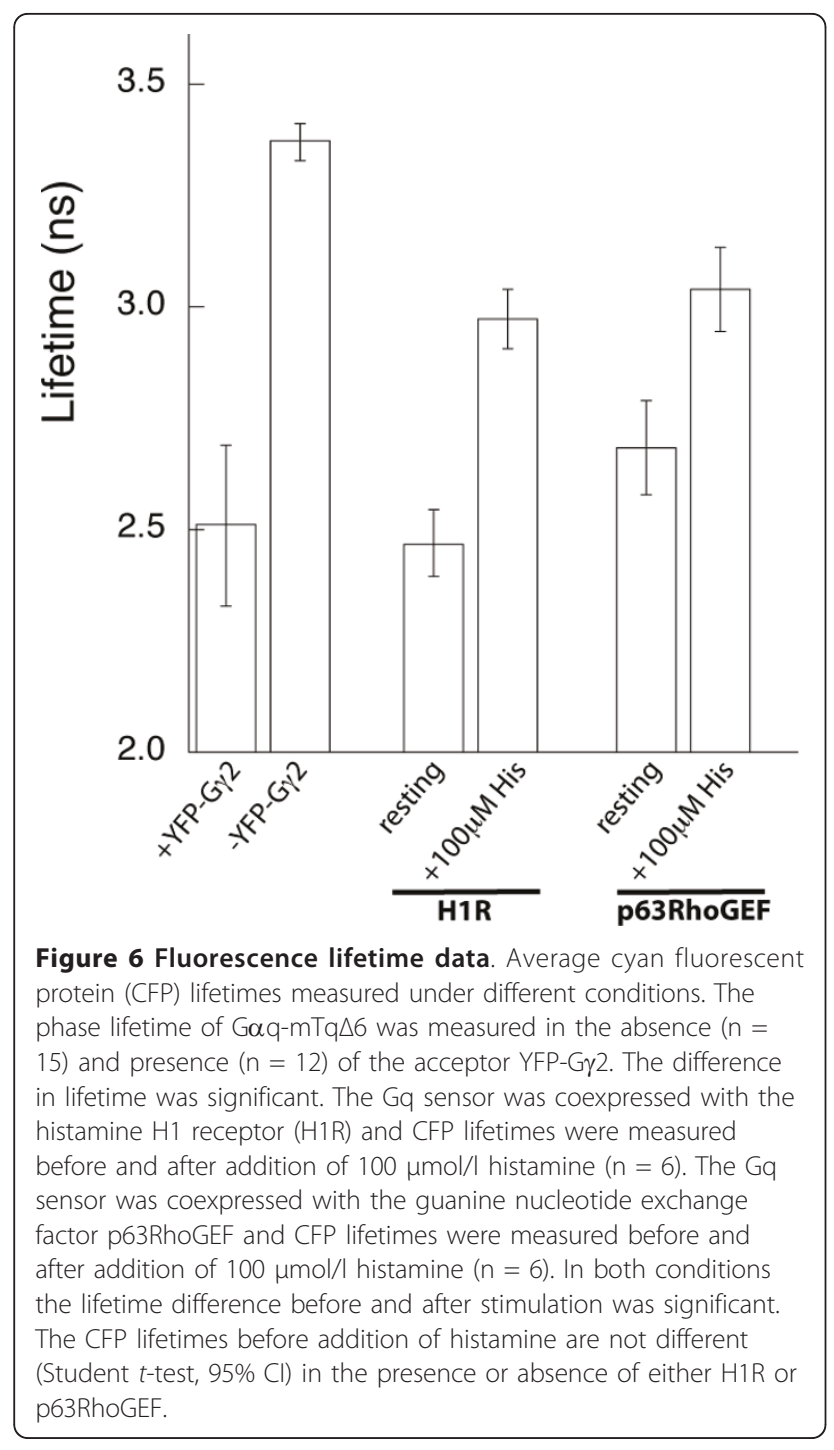

These results suggest ligand-independent activation of mechanosensitive H1R, leading to the activation of Gq. The activation of Gq, as detected by the decrease in FRET, led to activation of PLC $\beta$. We visualized the activity of PLC by monitoring the PH domain of PLC $\delta 1$ (PHס1), which specifically binds $\operatorname{PtdIns}(4,5) \mathrm{P}_{2}[46]$. Addition of a hypotonic stimulus caused the $\mathrm{PH} \delta 1$ domain to translocate from the plasma membrane to the cytosol, indicative of the hydrolysis of PtdIns $(4,5) \mathrm{P}_{2}$ (see Additional file 10). Consecutive addition of mepyramine did not affect the localization of $\mathrm{PH} \delta 1$, suggesting that the activation of H1R by stretch cannot be inhibited by an antagonist.

\section{Discussion}

\section{Characteristics of the Gq FRET sensor}

To evaluate functionality, we extensively tested the VFPtagged Gq in MEF cells deficient in Gq/11. The results

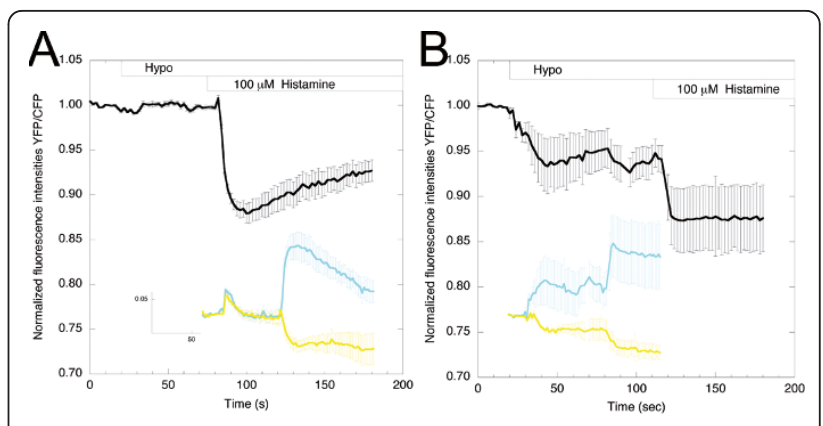

Figure 7 Ligand-independent activation of Gq. (A) Graph depicting the fluorescence resonance energy transfer (FRET) ratio (yellow fluorescent protein:monomeric Turquoise (YFP:mTq)) change upon the application of a hypotonic (Hypo) stimulus, followed by the addition of histamine $(100 \mu \mathrm{mol} / \mathrm{l})$ in HeLa cells expressing G $\alpha q-m T q \Delta 6, G \beta 1$ and YFP-G $\gamma 2$ ( $n=5$; error bars depict SE). (B) HeLa cells overexpressing the $\mathrm{H} 1$ receptor showed significant activation of $\mathrm{Gq}$ when the osmolality of the medium was reduced (Hypo). Subsequent addition of histamine yielded additional activation of $\mathrm{Gq}(\mathrm{n}=5)$.

in these cells showed that Gaq-mTq $\Delta 6$ effectively interacts with GPCRs and PLC $\beta$ (Figure 1). In addition, we can state that it can also form heterotrimers with $G \beta \gamma$ subunits, because receptors bound $\mathrm{G} \alpha$ subunits poorly and failed to trigger GDP exchange in the absence of G $\beta \gamma$ [47]. Moreover, we saw substantial FRET when Goq-mTq $\Delta 6$ was coexpressed with an YFP-tagged G $\gamma 2$.

The spatiotemporal characteristics of heterotrimeric $G$ protein activation are difficult to monitor, because direct measurement of GTP binding and hydrolysis is not feasible in living cells [48]. Instead, an increase in intracellular calcium, measured using calcium-sensitive fluorescent probes, is often used as an indicator of Gq activity. However, other heterotrimeric $\mathrm{G}$ proteins can cause increases in intracellular calcium by means of calcium entry from the extracellular environment, and by activation of PLC $\beta$ via G $\beta \gamma$ dimers [49-51]. In addition, increases in intracellular calcium triggered by Gq-coupled receptors are amplified signals that are modulated by downstream factors (for example, calcium-store depletion and regulation of effector function by $\mathrm{Ca}^{2+}$-activated kinases). Hence, they are not ideal to quantify the extent and dynamics of $\mathrm{G}$ protein activation. The FRET pair described here enables the direct measurement of heterotrimeric $\mathrm{G}$ protein activation. Through the use of an optimized fluorophore, the bright CFP variant mTurquoise (see Additional file 3), positioned in an orientation yielding a higher basal FRET efficiency level in the intact heterotrimer, in combination with YFP-G $\gamma 2$ as an acceptor, we were able to measure Gq activation kinetics in single cells with high temporal resolution.

The half-time of Gq activation of $350 \mathrm{~ms}$ is faster than those of $\mathrm{Gs}$ and $\mathrm{Gi}$ (450 and $690 \mathrm{~ms}$, respectively) 
(Figure 4) [14,17]. As receptor-G-protein interaction has been shown to be maximal after about $50 \mathrm{~ms}$ for several GPCR-G-protein pairs $[15,17,52]$, it is likely that the H1R-Gq interaction displays similar kinetics. Only a few $\mathrm{Gq}$ heterotrimers will be active at this early time point. Full activation of $\mathrm{Gq}$ proteins requires several hundred milliseconds, making G-protein activation (not receptor activation, receptor diffusion or receptor-G protein interaction) a limiting step in GPCR activation of downstream effectors. Interestingly, Mukhopadhyay and Ross [53] described the kinetics of $\mathrm{Gq}$ activation in vitro, and found GTP exchange to be rate-limiting for Gq activation. However, at cellular GTP levels, the GDP dissociation rate became rate-limiting. The GDP dissociation rate was found to be $1.5 / \mathrm{s}$, which correlates well with the rate of $\mathrm{Gq}$ activation determined by means of our FRET sensor in living cells.

Previous studies with FRET sensors on activation of other classes of heterotrimeric $G$ proteins showed a sustained activity in the continued presence of agonist [14-17,19,52]. For example, Gi activation only desensitizes noticeably upon removal of the agonist or addition of specific antagonists $[14,16]$. In our study, we also saw a long-lasting Gq activation in the presence of agonist when the histamine receptor was overexpressed (see Additional file 5), but the activation was readily reversed when an antagonist was added. By contrast, Gq activation was partially desensitized when endogenous histamine receptors were activated (Figure 5A). Presumably, this recovery is possible because GAPs are able to convert Gaq-GTP into Gaq-GDP under these conditions. Indeed, upon introduction of G188S in Gaq-mTq $\Delta 6$, the $\mathrm{Gq}$ activation kinetics changed compared with those of $\mathrm{G} \alpha \mathrm{q}-\mathrm{mTq} \Delta 6$; the response had a slower onset and prolonged activation (see Additional file 6). Clark and Lambert also described these phenomena previously [42]. However, in our case the observed phenotype was rather weak, which may imply that PLC $\beta$ is the physiological GAP in our system. Importantly, the doseresponse curve analysis (Figure 3 ) showed that the FRET change was also transient at low agonist concentrations under conditions in which histamine receptor was overexpressed. The histamine levels we used are in the physiological range, that is, whole blood levels were $25-65 \mathrm{ng} / \mathrm{ml}$ of histamine [54], corresponding to histamine concentrations in whole blood of $0.22-0.58 \mu \mathrm{mol} / \mathrm{l}$. Our data suggest that cells overexpressing H1R may show a small, transient $\mathrm{Gq}$ activation response to these histamine levels in blood.

\section{Influence of accessory proteins on the activation state of} Gq

Overexpression of p63RhoGEF led to an increase in the FRET ratio amplitude (Figure $5 \mathrm{C}$ ), but the Gaq- interaction mutant, p63RhoGEF-L475A, did not have an effect on the amplitude (see Additional file 8). It is likely that p63RhoGEF retains Gq in its active state by shielding it from the GAP PLC $\beta$, thereby accumulating GaqGTP.

The question of whether intact heterotrimers or dissociated G-proteins (G $\alpha$ q and G $\beta \gamma$ ) activate downstream effectors has not been resolved to date, and most of our knowledge has been obtained from structural studies with purified proteins. G $\alpha$ q-GDP and G $\beta \gamma$ interact through two interfaces. The most extensive interface is formed by residues close to and within switch I and II from the $G \alpha$ subunit. These residues contact G $\beta$ residues at the top of the propeller domain. The second interface is formed by the $\mathrm{N}$ terminus of $\mathrm{G} \alpha$ and the side of the $G \beta$ propeller $[2,55]$. G $\beta$ is most severely affected in binding to $\mathrm{G} \alpha$ when it contains mutations in the region that interacts with the $\mathrm{N}$ terminus of $\mathrm{G} \alpha$, indicating that the $\mathrm{N}$ terminus is crucial in mediating the interaction with G $\beta$ [56]. It may therefore be envisioned that, upon activation, the contact of $G \beta$ with the switch regions is lost, whereas its contact with the $\mathrm{N}$ terminus remains, as suggested by Gibson and Gilman [16]. This would enable an opening up of the trimer, allowing $G \alpha$ and $G \beta \gamma$ to interact with their downstream signalling partners. However, activation of certain effectors may require complete dissociation of the heterotrimer. Accessory proteins may cause dissociation of Gaq and $G \beta \gamma$ by forcing them apart. The recently published crystal structure of the $G$ protein-coupled receptor

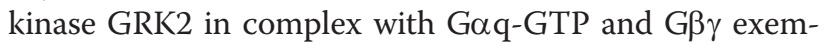
plifies this idea [57]. It showed that GRK2 interacts with G $\beta \gamma$ residues implicated in both interfaces, thereby probably causing trimer dissociation.

The increases in FRET ratio amplitude that we observed may be due to an increase in fully dissociated heterotrimers, which causes a loss of FRET. However, a loss in FRET can also be explained by a change in orientation between donor and acceptor fluorophore via the $\mathrm{k}^{2}$ factor in the equation that determines the Förster radius. Interestingly, even under conditions of maximal GEF and minimal GAP activity, we detected extensive FRET (20\%) between G $\alpha \mathrm{q}$ and G $\gamma 2$, indicating that the majority of $\mathrm{G} \alpha \mathrm{q}$ is still in close proximity to $\mathrm{G} \gamma 2$ (on average in the order of $7 \mathrm{~nm}$, based on the FRET Förster radius). These data would support the partial opening hypothesis as outlined above, implying that full dissociation does not occur. However, although it indicated that Gq is not fully dissociated under these maximal stimulation conditions, our method cannot distinguish between a partial dissociation leaving a fraction of non-dissociated heterotrimers with unaltered high FRET efficiency (25\%) and a full conformational change of all heterotrimers characterized by a lower 
FRET efficiency. Importantly, others have proposed a signalling role for the intact $\mathrm{Gq}$ heterotrimer [58].

\section{Ligand-independent activation of $\mathrm{H} 1 \mathrm{R}$ activates $\mathrm{Gq}$}

Ligand-independent activation of GPCRs is a new and not yet fully explored phenomenon. It was described by Mederos y Schnitzler et al. [45] in HEK293 cells and COS-7 cells overexpressing the histamine $\mathrm{H} 1$ receptor, among others. Conformational changes in GPCR (FRET-based measurements) upon addition of a hypotonic stimulus and consecutive receptor activation have been described for BK2R in bovine aortic endothelial cells [59], for PTH1R (FRET-based) in pre-osteoblastic cells [60], and for AT1R (determined by means of substituted cysteine accessibility mapping) in HEK293 cells [61]. Studying mechanotransduction is especially important with respect to its effects on the cardiovascular system. For instance, mechanical stress to cardiomyocytes can trigger hypertrophic responses [62]. Using our Gq activity sensor, we were able to monitor $\mathrm{Gq}$ activation upon application of a hypotonic stimulus. Overexpression of H1R was required to observe a ratio change. Interestingly, we did observe an increase in the ratio change of the Gq FRET sensor in the presence of endogenous H1R upon addition of histamine, after hypotonic swelling of the cells. This suggests that heterotrimeric G proteins are triggered to bind the endogenous $\mathrm{H} 1$ receptor upon hypotonic stress, which may lead to changes in orientation of or distance between a small fraction of trimers. This pre-accumulation at the H1R might explain the larger amplitude seen upon addition of histamine, compared with that seen without prior exposure to hypotonic stress (Figure 5A).

Determination of H1R expression levels showed that in our cells overexpression produced an average of 710 $\mathrm{fmol} / \mathrm{mg}$ binding sites. Similarly, in A7r5 cells derived from the aorta (a mechano-insensitive tissue) overexpression of the AT1 receptor of about 15 times ( 88 $\mathrm{fmol} / \mathrm{mg}$ versus $1305 \mathrm{fmol} / \mathrm{mg}$ ) induced mechanosensitivity [45]. Moreover, the expression of AT1R in the aorta has been described to be $5 \mathrm{fmol} / \mathrm{mg}$ [63], whereas it can be up to $200 \mathrm{fmol} / \mathrm{mg}$ in the afferent arterioles (a mechanosensitive tissue) [64].

A conformational change in the AT1 receptor upon mechanical stress has been described [61]. Currently, it is not clear how this conformational change is triggered, and whether all mechanosensitive GPCRs undergo a similar change in conformation. It is likely that a FRET approach may shed more light on this matter.

\section{Conclusions}

By virtue of the optimized Gq FRET sensor described in this paper, the activation of Gq can now directly be measured with high spatial and temporal resolution in single living cells without having to rely on pharmacological inhibitors to delineate the involvement of specific signalling pathways. As a result we have determined $k_{\text {on }}$ of $\mathrm{Gq}$ for the first time. It is likely that FRET-based sensors for the measurement of other classes of $G$ proteins, which employ ECFP as donor and EYFP-G $\beta 1$ as acceptor, will be substantially improved by incorporating (truncated and monomerized) mTurquoise and using YFP-G $\gamma 2$ as acceptor.

Inhibitors of $\mathrm{G}$ proteins are attractive drug candidates [47]. The fact that overexpression of the $C$ terminus of Gaq has a positive effect on cardiac hypertrophy indicates a possible strategy for preventing pathophysiological signalling [7]. The FRET pair we developed may aid in the search for new drugs by facilitating highly sensitive $\mathrm{Gq}$ activity measurements in living cells. Moreover, we have shown that this tool can be used to study the kinetics of heterotrimeric $G$ protein signalling and the influence of accessory proteins.

\section{Methods \\ DNA constructs}

The pcDNA3.1+ plasmids containing the cDNA encod-

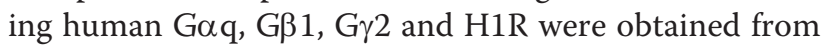
the Missouri S\&T cDNA Resource Center (http://www. cdna.org). We inserted monomeric (A206K) spectral variants of GFP in the $\alpha \mathrm{B}-\alpha \mathrm{C}$ loop of G $\alpha q$ in between residues 127 and 128, thereby changing N126 into D126. The linkers present in the Gaq-YFP construct are SGGGGS at the $\mathrm{N}$ terminus of the FP and SGGSGD at the $\mathrm{C}$ terminus of the FP. To make the Gaq-mTq $\Delta 6$ construct, the last six amino acids of $\mathrm{mTq}$ were removed. The linkers present in this construct are SGGGGS at the $\mathrm{N}$ terminus of the FP and I at the $\mathrm{C}$ terminus of the FP. Gaq-YFP was amplified by means of PCR and inserted into the retroviral vector $\mathrm{pBABE}$-puromycin (Addgene Inc, Cambridge, MA, USA). Detailed sequence information of the construct is available upon request.

To make YFP-G $\gamma 2$, we amplified G $\gamma 2$ by means of PCR and cloned it behind circular-permutated Venus derived from YCam3.60 [65] (kind gift of Dr A Miyawaki, Riken, Wako, Japan). The full-length p63RhoGEF was a gift from Dr J Sondek (University of North Carolina, Chapel Hill, NC, USA); Gaq-ECFP was provided by Dr C. Berlot (Weis Center for Research, Danville, PA, USA)and EYFP-G $\beta 1$ by Dr S Ikeda (National Institutes of Health, Bethesda, MD, USA). Gaq-ECFP was transferred from pcDNAI to a high copy number plasmid by replacing EGFP in the pEGFP-C1 plasmid, using the restriction enzymes SnaBI and PspOMI.

\section{Cell culture and transfection/transduction}

All cell culture media were from Invitrogen (Breda, The Netherlands). MEF cells devoid of Gaq/11 subunits 
[33], derived from Gaq/11 knockout mice were cultured in Dulbecco's modified Eagle's medium (DMEM) (\#21969-035)] supplied with $1 \times$ non-essential amino acids, $10 \%$ fetal bovine serum (FBS), $1 \times$ L-glutamine, $100 \mathrm{U} / \mathrm{ml}$ penicillin and $100 \mu \mathrm{g} / \mathrm{ml}$ streptomycin. For transduction of these cells, the retroviral vector $\mathrm{pBABE}$ Gaq-YFP was transfected into Phoenix-Eco package cells, and the supernatant, containing viral particles, was harvested 48 hours after infection. Cells were incubated with $1 \mathrm{ml}$ of this supernatant in the presence of $10 \mu \mathrm{l}$ Dotap $(1 \mathrm{mg} / \mathrm{ml})$ (Roche, Indianapolis, IN, USA) and after 48 hours, cells were grown for 2 weeks on media containing $2 \mu \mathrm{g} / \mathrm{ml}$ puromycin for selection. For imaging, these cells were cultured on glass coverslips and loaded with the calcium indicator Fura Red $(6 \mu \mathrm{g} / \mathrm{ml}$ final concentration) (Fura Red AM; Molecular Probes, Eugene, OR, USA) for 30 minutes at room temperature. For imaging, non-transduced MEF cells were cultured on glass coverslips and transfected (Lipofectamine reagent; Invitrogen) with plasmids encoding Gaq$\mathrm{mTq} \Delta 6$. After overnight incubation at $37^{\circ} \mathrm{C}$ and $5 \%$ $\mathrm{CO}_{2}$, the cells were loaded with Fura Red and mounted in a cell chamber (Attofluor; Invitrogen), submerged in medium $(140 \mathrm{mmol} / \mathrm{l} \mathrm{NaCl}, 5 \mathrm{mmol} / \mathrm{l} \mathrm{KCl}, 1 \mathrm{mmol} / \mathrm{l}$ $\mathrm{MgCl}_{2}, 1 \mathrm{mmol} / 1 \mathrm{CaCl}_{2}, 10 \mathrm{mmol} / \mathrm{l}$ glucose, $20 \mathrm{mmol} / \mathrm{l}$ HEPES $\mathrm{pH}$ 7.4) and viewed under a confocal microscope.

HeLa cells (American Tissue Culture Collection; Manassas, VA, USA) were cultured in DMEM plus Glutamax (\#61965-059), 10\% FBS, $100 \mathrm{U} / \mathrm{ml}$ penicillin and $100 \mu \mathrm{g} /$ $\mathrm{ml}$ streptomycin. Transfection and preparation for imaging purposes were similar to the procedures described above for MEF cells.

\section{Confocal microscopy}

Mammalian cells were imaged using a confocal laserscanning microscope (LSM 510; Carl Zeiss GmbH, Oberkochen, Germany) with an oil-immersion objective (Plan-A 63×/1.4; Carl Zeiss GmbH). Samples were excited with a 488-nm argon laser. For YFP/Fura Red, the following settings were used a primary dichroic mirror $(488 \mathrm{~nm})$ and a secondary dichroic mirror $(570 \mathrm{~nm})$, thereby splitting the Fura Red fluorescence from the YFP fluorescence. The 505 to $550 \mathrm{~nm}$ bandpass filter was used to yield the YFP image, and the long-pass 650 $\mathrm{nm}$ filter was used to obtain the Fura Red image. MEF cells were stimulated with $1 \mu \mathrm{mol} / \mathrm{l}$ (final concentration) BK (Sigma-Aldrich, St. Louis, MO, USA), and the Fura Red intensity was followed in time as a measure of intracellular calcium levels. The $\mathrm{n}$ determinations are derived from different cells, expressing different amounts of protein from the same batch of MEF cells on different days, and throughout the study, cells from different experiments were pooled and are displayed as $\mathrm{n}$ determinations.

Fast imaging was performed on a confocal microscope (A1; Nikon, Tokyo, Japan). The excitation light was from a 443-nm laser, which was reflected onto the sample by a $457 / 514$ dichroic mirror. Fluorescence emission was separated by a secondary dichroic mirror $(515 \mathrm{~nm})$. $\mathrm{mTq}$ fluorescence was filtered through a 464 to $499 \mathrm{~nm}$ emission filter, and sensitized emission was filtered through a 525 to $555 \mathrm{~nm}$ emission filter. A $40 \times$ objective was used, and the pinhole was completely opened. The frame size was $512 \times 128$ pixels, and images were acquired at 15 frames per second (60 frames/s with four line averages). The curve was fitted using

$$
y=\left(1-\exp \left(-\mathrm{k}_{\mathrm{on}} \times \mathrm{t}\right)\right)
$$

The half-time of the first-order reaction is given by:

$$
\mathrm{t}_{1 / 2}=\ln (2) / \mathrm{k}_{\mathrm{on}} \text {. }
$$

\section{Wide-field fluorescence microscopy}

Ratiometric FRET measurements in HeLa cells were performed using a wide-field fluorescence microscope (Axiovert $200 \mathrm{M}$; Carl Zeiss $\mathrm{GmbH}$ ) kept at $37^{\circ} \mathrm{C}$, equipped with an oil-immersion objective (Plan-Neofluar 40x/1.30; Carl Zeiss $\mathrm{GmbH}$ ) and a xenon arc lamp with monochromator (Cairn Research, Faversham, Kent, UK). Images were recorded with a cooled chargedcoupled device camera (Coolsnap HQ, Roper Scientific, Tucson, AZ, USA). Fluorophores were excited with 420 $\mathrm{nm}$ light (slit width $30 \mathrm{~nm}$ ), $\mathrm{mTq}$ emission was detected with the bandpass 470/30 filter, and YFP emission was detected with the BP535/30 filter by turning the filter wheel. The exposure time for each image was $200 \mathrm{~ms}$. HeLa cells were stimulated with $100 \mu \mathrm{mol} / \mathrm{l}$ (final concentration) histamine (Sigma-Aldrich) and mTq/YFP emission was followed in time. Pyrilamine (mepyramine) (Sigma-Aldrich) was added to obtain a final concentration of $10 \mu \mathrm{mol} / \mathrm{l}$.

\section{Fluorescence lifetime imaging microscopy}

Frequency-domain FLIM measurements were performed using the apparatus described previously [66], equipped with an oil-immersion objective (Plan Apochromat 63×/ 1.4 objective; Carl Zeiss $\mathrm{GmbH}$ ). Samples were excited by means of a $442 \mathrm{~nm}$ helium-cadmium laser modulated at $75.1 \mathrm{MHz}$ and a BP 480/40 emission filter was used to detect $\mathrm{mTq}$ fluorescence. FLIM stacks of 24 phase images permutated in recording order [67] were acquired with an exposure time of about 0.1 to $0.5 \mathrm{sec}-$ onds each. FRET efficiency was calculated as follows: 


$$
\mathrm{E}=1-\tau_{\mathrm{DA}} / \tau_{\mathrm{D}}
$$

where $\tau_{\mathrm{DA}}$ and $\tau_{\mathrm{D}}$ are the donor lifetimes in the presence and absence of an acceptor, respectively.

\section{Membrane stretch}

A hypotonic stimulus was applied by replacing $0.5 \mathrm{ml}$ medium by $20 \mathrm{mmol} / \mathrm{l}$ HEPES $\mathrm{pH}$ 7.4.

\section{WB}

The antibody against Goq/11 (sc-46972, C-16; Santa Cruz Biochemicals, Santa Cruz, CA, USA) was directed against an epitope near the $C$ terminus.

\section{H1R expression level determination}

HeLa cells were scraped from a $90 \mathrm{~mm}$ petri dish, and resuspended in binding buffer $\left(50 \mathrm{mmol} / \mathrm{l} \mathrm{Na}_{2} / \mathrm{K}\right.$-phosphate buffer $\mathrm{pH}$ 7.4), and mixed by sonication to ensure a homogenous membrane suspension. The membrane suspension was added to premixed radioligand/competitor or radioligand/buffer solutions, and incubated for approximately 1 hour at room temperature on a shaking table $(750 \mathrm{rpm})$. Free radioligand was separated from bound radioligand by filtration through a GF/C filterplate (PerkinElmer Corp., Waltham, MA, USA) presoaked with $0.5 \%$ polyethyleneimine. Scintillation fluid was added to the filter plate, and radioactivity was measured in a Wallac micro $\beta$ counter. Each well contained $25 \mu \mathrm{l}$ competitor (final concentration: $10 \mu \mathrm{mol} / \mathrm{l}$ mianserin) or binding buffer, $25 \mu \mathrm{l}$ radioligand $(25.8 \mathrm{Ci} /$ mmol $\left[{ }^{3} \mathrm{H}\right]$-mepyramine) and $50 \mu \mathrm{l}$ membrane suspension.

\section{Additional material}

Additional File 1: Goq-monomeric visible fluorescent protein (mVFP) expression in various cell lines (A) Madin-Darby canine kidney (MDCK) cells expressing Gaq-monomeric yellow fluorescent protein (mYFP); (B) N1E-115 neuroblastoma cells expressing Gaq-mYFP; (C) HEK293 cells expressing Gaq-mYFP; (D) HeLa cells expressing Gaq$\mathrm{mTq} \triangle 6$.

\section{Additional File 2: Expression of $\mathrm{G} \alpha q$ in mouse embryonic} fibroblasts (MEF) and HeLa cell lines Transfected, transduced or untreated cells were treated with trypsin and lysed. Each lane was loaded with $40 \mu \mathrm{g}$ of protein. Western blotting was performed with an antibody against G $\alpha q / 11$ (diluted 1:1000) and exposed for 30 seconds. Lane 1 contains wild-type HeLa cells; lane 2 contains HeLa cells transfected with Gaq-mTq $\Delta 6$; lane 3 contains MEFq/11 $1^{-/}$cells; lane 4 contains MEFq/11 $11^{--}$cells transduced with G $\alpha q-m Y F P$ and lane 5 contains wild-type MEF cells.

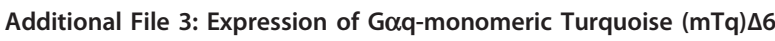
versus $\mathrm{G} \alpha \mathrm{q}$-enhanced cyan fluorescent protein (ECFP) in HeLa cells Representative images of HeLa cells expressing Gaq-ECFP (top) or Gaq$\mathrm{mTq} \triangle 6$ (bottom), 2 days after transfection with equal amounts of DNA. The images were acquired with the same exposure time and contrast settings.

Additional File 4: Gq fluorescence resonance energy transfer (FRET) movie Movie displaying the change in FRET ratio upon addition of histamine $(100 \mu \mathrm{mol} / \mathrm{l})$, followed by the addition of mepyramine (10 $\mu \mathrm{mol} / \mathrm{l}$ ) in HeLa cells expressing Gaq-monomeric Turquoise (mTq) $\Delta 6$, $\mathrm{G} \beta 1$, yellow fluorescent protein (YFP)-G $\gamma 2$ and histamine 1 receptor (H1R).

Additional File 5: Long-term activation of Gq Graph depicting the duration of the change in fluorescence resonance energy transfer (FRET) ratio (yellow fluorescent protein:monomeric Turquoise (YFP:mTq)) in the continuous presence of histamine in HeLa cells expressing Gaqmonomeric Turquoise (mTq) $\triangle 6, G \beta 1$, YFP-G $\gamma 2$ and histamine 1 receptor (H1R).

Additional File 6: Regulators of G-protein signalling (RGS)-sensitive versus RGS-insensitive $\mathbf{G q}(\mathbf{A})$ The fluorescence resonance energy transfer (FRET) ratio change (yellow fluorescent protein:monomeric Turquoise (YFP:mTq)) upon addition of histamine $(100 \mu \mathrm{mol} / \mathrm{l})$ in HeLa cells expressing G $\alpha q-m T q \Delta 6, G \beta 1$ and YFP-G $\gamma 2$ ( $n=4$; error bars depict $\mathrm{SE}$ ). (B) The FRET ratio change (YFP:mTq) upon addition of histamine $(100 \mu \mathrm{mol} / \mathrm{l})$ in HeLa cells expressing $\mathrm{G} \alpha \mathrm{q}-\mathrm{mTq} \Delta 6-\mathrm{G} 188 \mathrm{~S}, \mathrm{G} \beta 1$ and YFP$\mathrm{G} \gamma 2(\mathrm{n}=8)$.

Additional File 7: Effect of mepyramine on Gq fluorescence resonance energy transfer (FRET) ratio changes in the presence of the guanine nucleotide exchange factor p63RhoGEF Representative trace depicting the FRET ratio change (yellow fluorescent protein: monomeric Turquoise (YFP:mTq) ) upon addition of histamine $(100 \mu \mathrm{mol} /$ I) in HeLa cells coexpressing G $\alpha q-m T q \Delta 6, G \beta 1$, YFP-G $\gamma 2$ and p63RhoGEF. Addition of the histamine 1 receptor $(\mathrm{H} 1 \mathrm{R})$ inverse agonist mepyramine $(10 \mu \mathrm{mol} / \mathrm{l})$ reversed the ratio change induced by histamine. (Inset) the $\mathrm{mTq}$ and YFP intensity traces from which the ratio was derived.

Additional File 8: Overview of observed fluorescence resonance energy transfer (FRET) ratio changes Histogram depicting the normalized FRET ratio (yellow fluorescent protein:monomeric Turquoise (YFP:mTq)) changes upon histamine stimulation, observed in cells expressing G $\alpha q-m T q \Delta 6, G \beta 1$ and YFP-G $\gamma 2$ (wild-type (wt); $n=54$ ); cells expressing G $\alpha q-m T q \Delta 6, G \beta 1$, YFP-G $\gamma 2$ and histamine 1 receptor (H1R, $n$ $=8$ ); cells expressing G $\alpha q-m T q \Delta 6, G \beta 1$, YFP-G $\gamma 2$ and the guanine nucleotide exchange factor p63RhoGEF ( $p 63, n=29$ ); cells expressing G $\alpha q-m T q \Delta 6, G \beta 1$, YFP-G $\gamma 2$ and p63RhoGEF-L475A (p63LA, $n=15$ ). The error bars depict SE.

Additional File 9: Lifetime data (A) Gaq-monomeric Turquoise (mTq) $\triangle 6$ intensity (C) and phase lifetime image in the absence of acceptor (yellow fluorescent protein) YFP-G $\gamma 2$. (B) G $\alpha q-m T q \Delta 6$ intensity and (D) phase lifetime image in the presence of acceptor YFP-G $\gamma 2$ 2. (E) Phase lifetime histogram; lifetime distribution of the depicted cells in the presence (left population) and in the absence of the acceptor (right population). (F-J) Gaq-mTq $\Delta 6$ intensity image in the presence of acceptor YFP-G $\gamma_{2}$ and histamine 1 receptor (H1R) (F) before and (G) after addition of histamine. Phase lifetime image of $\mathrm{G} \alpha q-\mathrm{mTq} \Delta 6 \mathbf{( H )}$ before and (I) after addition of histamine. (J) Phase lifetime histogram; lifetime distribution of the depicted cells (left) before and (right) after addition of histamine. (K-O) G $\alpha q-\mathrm{mTq} \Delta 6$ intensity image in the presence of acceptor YFP-G $\gamma_{2}$ and the guanine nucleotide exchange factor p63-RhoGEF (K) before and (L) after addition of histamine. Phase lifetime image of G $\alpha$ q$m T q \Delta 6(\mathbf{M})$ before and $(\mathbf{N})$ after addition of histamine. $(\mathbf{O})$ Phase lifetime histogram; lifetime distribution of the depicted cells (left) before and (right) after addition of histamine.

Additional File 10: $\mathrm{Ptd} \ln s(4,5) \mathrm{P}_{2}$ hydrolysis upon hypotonic stimulus (A) Green fluorescent protein (GFP)-PH was used as an indicator for Ptdlns(4,5)P2 levels, and was found to be localized predominantly at the plasma membrane of HeLa cells. (C) Membrane localization was quantified by means of a line profile plot. Upon applying the hypotonic stimulus (B) the PH domain translocated partially to the cytoplasm, which is also evident from (D) the line profile plot, showing decreased membrane intensity and increased cytoplasmic intensity.

\section{Acknowledgements}

We thank Dr N. Divecha (Dutch Cancer Institute, Amsterdam, The Netherlands, presently at University of Manchester, Manchester, UK) and Dr K.C. Crosby (Molecular Cytology, University of Amsterdam) for technical 
support and stimulating discussions, and Drs Miyawaki, Sondek, Ikeda and Berlot for sharing their constructs. We thank Dr H.F. Vischer (VU University Amsterdam) for assistance in determining H1R expression levels. Part of this work was supported by the EU integrated project on 'Molecular Imaging' LSHG-CT-2003-503259.

\section{Author details}

'Swammerdam Institute for Life Sciences, Section of Molecular Cytology, van Leeuwenhoek Centre for Advanced Microscopy, University of Amsterdam, Science Park 904, 1098 XH, Amsterdam, The Netherlands. ${ }^{2}$ Nijmegen Centre for Molecular Life Sciences, Department of Biochemistry, Radboud University Nijmegen Medical Centre, Geert Grooteplein 28, 6525 GA Nijmegen, The Netherlands. ${ }^{3}$ Department of Chemistry and Pharmaceutical Sciences, Division of Medicinal Chemistry, Leiden/Amsterdam Center for Drug Research, VU University Amsterdam, De Boelelaan 1083, 1081 HV Amsterdam, The Netherlands. ${ }^{4}$ Department of Pharmacology, Max-PlanckInstitute for Heart and Lung Research, Ludwigstrasse 43, 61231 Bad Nauheim, Germany.

\section{Authors' contributions}

MAH designed the experiments, acquired and analyzed the data, and wrote the manuscript. JG designed the experiments, acquired the data, and was involved in the writing/revision of the manuscript. LvW constructed $\mathrm{Ga}_{\mathrm{q}}$ mTq $\triangle 6$ and performed western blot analyses. SN determined the H1R expression levels. EMM provided technical assistance with the microscope (Nikon A1). SO provided the MEFq/11/- cell line, gave advice with respect to experiments, and was involved in the revision of the manuscript.,TWJG designed the experiments, and was involved in the writing and revision of the manuscript. All authors read and approved the final manuscript.

\section{Received: 17 March 2011 Accepted: 27 May 2011}

Published: 27 May 2011

\section{References}

1. Cabrera-Vera TM, Vanhauwe J, Thomas TO, Medkova M, Preininger A, Mazzoni MR, Hamm HE: Insights into G protein structure, function, and regulation. Endocr Rev 2003, 24(6):765-781.

2. Wall MA, Coleman DE, Lee E, Iniguez-Lluhi JA, Posner BA, Gilman AG, Sprang SR: The structure of the $\mathrm{G}$ protein heterotrimer $\mathrm{Gi}$ alpha 1 beta 1 gamma 2. Cell 1995, 83(6):1047-1058.

3. Taylor SJ, Chae HZ, Rhee SG, Exton JH: Activation of the beta 1 isozyme of phospholipase $\mathrm{C}$ by alpha subunits of the $\mathrm{Gq}$ class of $\mathrm{G}$ proteins. Nature 1991, 350(6318):516-518

4. Booden MA, Siderovski DP, Der CJ: Leukemia-associated Rho guanine nucleotide exchange factor promotes $\mathrm{G}$ alpha q-coupled activation of RhoA. Mol Cell Biol 2002, 22(12):4053-4061.

5. Lutz S, Freichel-Blomquist A, Yang Y, Rumenapp U, Jakobs KH, Schmidt M, Wieland $\mathrm{T}$ : The guanine nucleotide exchange factor p63RhoGEF, a specific link between $\mathrm{Gq} / 11$-coupled receptor signaling and RhoA. J Biol Chem 2005, 280(12):11134-11139.

6. Lutz S, Shankaranarayanan A, Coco C, Ridilla M, Nance MR, Vettel C, Baltus D, Evelyn CR, Neubig RR, Wieland T, et al: Structure of Galphaqp63RhoGEF-RhoA complex reveals a pathway for the activation of RhoA by GPCRs. Science 2007, 318(5858):1923-1927.

7. Akhter SA, Luttrell LM, Rockman HA, laccarino G, Lefkowitz RJ, Koch WJ: Targeting the receptor-Gq interface to inhibit in vivo pressure overload myocardial hypertrophy. Science 1998, 280(5363):574-577.

8. Wettschureck N, Rutten H, Zywietz A, Gehring D, Wilkie TM, Chen J, Chien KR, Offermanns S: Absence of pressure overload induced myocardial hypertrophy after conditional inactivation of Galphaq/ Galpha11 in cardiomyocytes. Nat Med 2001, 7(11):1236-1240.

9. Dorn GW: Physiologic growth and pathologic genes in cardiac development and cardiomyopathy. Trends Cardiovasc Med 2005, 15(5):185-189.

10. Offermanns S, Hashimoto K, Watanabe M, Sun W, Kurihara H, Thompson RF, Inoue $Y$, Kano M, Simon MI: Impaired motor coordination and persistent multiple climbing fiber innervation of cerebellar Purkinje cells in mice lacking Galphaq. Proc Natl Acad Sci USA 1997, 94(25):14089-14094.

11. Wettschureck N, van der Stelt M, Tsubokawa $H$, Krestel H, Moers A, Petrosino S, Schutz G, Di Marzo V, Offermanns S: Forebrain-specific inactivation of $\mathrm{Gq} / \mathrm{G} 11$ family $\mathrm{G}$ proteins results in age-dependent epilepsy and impaired endocannabinoid formation. Mol Cell Biol 2006 26(15):5888-5894.

12. Offermanns S, Toombs CF, Hu YH, Simon Ml: Defective platelet activation in G alpha(q)-deficient mice. Nature 1997, 389(6647):183-186.

13. Wettschureck N, Moers A, Offermanns S: Mouse models to study Gprotein-mediated signaling. Pharmacol Ther 2004, 101(1):75-89.

14. Bunemann M, Frank M, Lohse MJ: Gi protein activation in intact cells involves subunit rearrangement rather than dissociation. Proc Natl Acad Sci USA 2003, 100(26):16077-16082.

15. Frank M, Thumer L, Lohse MJ, Bunemann M: G Protein activation without subunit dissociation depends on a G\{alpha\}(i)-specific region. J Biol Chem 2005, 280(26):24584-24590.

16. Gibson SK, Gilman AG: Gialpha and Gbeta subunits both define selectivity of $\mathrm{G}$ protein activation by alpha2-adrenergic receptors. Proc Natl Acad Sci USA 2006, 103(1):212-217.

17. Hein P, Rochais F, Hoffmann C, Dorsch S, Nikolaev VO, Engelhardt S, Berlot CH, Lohse MJ, Bunemann M: Gs activation is time-limiting in initiating receptor-mediated signaling. J Biol Chem 2006, 281(44):33345-33351

18. Janetopoulos C, Jin T, Devreotes P: Receptor-mediated activation of heterotrimeric G-proteins in living cells. Science 2001, 291(5512):2408-2411.

19. Jensen JB, Lyssand JS, Hague C, Hille B: Fluorescence changes reveal kinetic steps of muscarinic receptor-mediated modulation of phosphoinositides and Kv7.2/7.3 K+ channels. J Gen Physiol 2009, 133(4):347-359.

20. Sengupta P, Philip F, Scarlata S: Caveolin-1 alters $\mathrm{Ca}(2+)$ signal duration through specific interaction with the $\mathrm{G}$ alpha $q$ family of $\mathrm{G}$ proteins. J Cell Sci 2008, 121(Pt 9):1363-1372.

21. Yi TM, Kitano H, Simon Ml: A quantitative characterization of the yeast heterotrimeric G protein cycle. Proc Natl Acad Sci USA 2003, 100(19):10764-10769.

22. Sheridan $\mathrm{DL}$, Berlot $\mathrm{CH}$, Robert $\mathrm{A}$, Inglis FM, Jakobsdottir $\mathrm{KB}$, Howe $\mathrm{JR}$, Hughes TE: A new way to rapidly create functional, fluorescent fusion proteins: random insertion of GFP with an in vitro transposition reaction. BMC Neurosci 2002, 3:7.

23. Yu JZ, Rasenick MM: Real-time visualization of a fluorescent $\mathrm{G}(\mathrm{alpha})(\mathrm{s})$ : dissociation of the activated $\mathrm{G}$ protein from plasma membrane. $\mathrm{Mol}$ Pharmacol 2002, 61(2):352-359.

24. Wedegaertner PB, Chu DH, Wilson PT, Levis MJ, Bourne HR: Palmitoylation is required for signaling functions and membrane attachment of $\mathrm{Gq}$ alpha and Gs alpha. J Biol Chem 1993, 268(33):25001-25008.

25. Wilson PT, Bourne HR: Fatty acylation of alpha z. Effects of palmitoylation and myristoylation on alpha z signaling. J Biol Chem 1995, 270(16):9667-9675.

26. Hughes $T E$, Zhang $H$, Logothetis $D E$, Berlot $C H$ : Visualization of a functional Galpha q-green fluorescent protein fusion in living cells. Association with the plasma membrane is disrupted by mutational activation and by elimination of palmitoylation sites, but not be activation mediated by receptors or AlF4. J Biol Chem 2001 , 276(6):4227-4235.

27. Zacharias DA, Violin JD, Newton AC, Tsien RY: Partitioning of lipidmodified monomeric GFPs into membrane microdomains of live cells. Science 2002, 296(5569):913-916.

28. Jares-Erijman EA, Jovin TM: Imaging molecular interactions in living cells by FRET microscopy. Curr Opin Chem Biol 2006, 10(5):409-416.

29. Pietraszewska-Bogiel A, Gadella TW: FRET microscopy: from principle to routine technology in cell biology. J Microsc 2010 .

30. Goedhart J, van Weeren L, Hink MA, Vischer NO, Jalink K, Gadella TW Jr: Bright cyan fluorescent protein variants identified by fluorescence lifetime screening. Nat Methods 2010, 7(2):137-139.

31. Truong K, Sawano A, Mizuno H, Hama H, Tong Kl, Mal TK, Miyawaki A, Ikura M: FRET-based in vivo Ca2+ imaging by a new calmodulin-GFP fusion molecule. Nat Struct Biol 2001, 8(12):1069-1073.

32. Ruiz-Velasco V, Ikeda SR: Functional expression and FRET analysis of green fluorescent proteins fused to G-protein subunits in rat sympathetic neurons. J Physiol 2001, 537(Pt 3):679-692.

33. Zywietz A, Gohla A, Schmelz M, Schultz G, Offermanns S: Pleiotropic effects of Pasteurella multocida toxin are mediated by $\mathrm{Gq}$-dependent and -independent mechanisms. involvement of Gq but not G11. J Biol Chem 2001, 276(6):3840-3845 
34. Vogt S, Grosse R, Schultz G, Offermanns S: Receptor-dependent RhoA activation in G12/G13-deficient cells: genetic evidence for an involvement of Gq/G11. J Biol Chem 2003, 278(31):28743-28749.

35. Evanko DS, Thiyagarajan MM, Siderovski DP, Wedegaertner PB: Gbeta gamma isoforms selectively rescue plasma membrane localization and palmitoylation of mutant Galphas and Galphaq. J Biol Chem 2001, 276(26):23945-23953.

36. Bakker RA, Nicholas MW, Smith TT, Burstein ES, Hacksell U, Timmerman $H$, Leurs R, Brann MR, Weiner DM: In vitro pharmacology of clinically used central nervous system-active drugs as inverse $\mathrm{H}(1)$ receptor agonists. $J$ Pharmacol Exp Ther 2007, 322(1):172-179.

37. Bakker RA, Wieland K, Timmerman H, Leurs R: Constitutive activity of the histamine $H(1)$ receptor reveals inverse agonism of histamine $H(1)$ receptor antagonists. Eur J Pharmacol 2000, 387(1):R5-7.

38. Fitzsimons CP, Monczor F, Fernandez N, Shayo C, Davio C: Mepyramine, a histamine $\mathrm{H} 1$ receptor inverse agonist, binds preferentially to a $\mathrm{G}$ protein-coupled form of the receptor and sequesters $G$ protein. J Biol Chem 2004, 279(33):34431-34439.

39. Tilly BC, Tertoolen LG, Lambrechts AC, Remorie R, de Laat SW, Moolenaar WH: Histamine-H1-receptor-mediated phosphoinositide hydrolysis, $\mathrm{Ca} 2+$ signalling and membrane-potential oscillations in human HeLa carcinoma cells. Biochem J 1990, 266(1):235-243.

40. Berstein G, Blank JL, Jhon DY, Exton JH, Rhee SG, Ross EM: Phospholipase C-beta 1 is a GTPase-activating protein for $\mathrm{Gq} / 11$, its physiologic regulator. Cell 1992, 70(3):411-418.

41. Hepler JR, Berman DM, Gilman AG, Kozasa T: RGS4 and GAIP are GTPaseactivating proteins for $\mathrm{Gq}$ alpha and block activation of phospholipase C beta by gamma-thio-GTP-Gq alpha. Proc Natl Acad Sci USA 1997, 94(2):428-432.

42. Clark MA, Lambert NA: Endogenous regulator of G-protein signaling proteins regulate the kinetics of Galphaq/11-mediated modulation of ion channels in central nervous system neurons. Mol Pharmacol 2006, 69(4):1280-1287.

43. Rojas RJ, Yohe ME, Gershburg S, Kawano T, Kozasa T, Sondek J: Galphaq directly activates p63RhoGEF and Trio via a conserved extension of the Dbl homology-associated pleckstrin homology domain. J Biol Chem 2007, 282(40):29201-29210

44. Bastiaens $\mathrm{PI}$, Squire A: Fluorescence lifetime imaging microscopy: spatial resolution of biochemical processes in the cell. Trends Cell Biol 1999, 9(2):48-52.

45. Mederos y Schnitzler M, Storch U, Meibers S, Nurwakagari P, Breit A, Essin K, Gollasch M, Gudermann T: Gq-coupled receptors as mechanosensors mediating myogenic vasoconstriction. EMBO J 2008, 27(23):3092-3103.

46. Stauffer TP, Ahn S, Meyer T: Receptor-induced transient reduction in plasma membrane Ptdlns(4,5)P2 concentration monitored in living cells. Curr Biol 1998, 8(6):343-346.

47. Freissmuth $M$, Waldhoer $M$, Bofill-Cardona $E$, Nanoff $C$ : $G$ protein antagonists. Trends Pharmacol Sci 1999, 20(6):237-245.

48. Milligan G: Principles: extending the utility of [35S]GTP gamma S binding assays. Trends Pharmacol Sci 2003, 24(2):87-90.

49. Camps M, Carozzi A, Schnabel P, Scheer A, Parker PJ, Gierschik P: Isozymeselective stimulation of phospholipase C-beta 2 by $\mathrm{G}$ protein beta gamma-subunits. Nature 1992, 360(6405):684-686.

50. Kamp TJ, Hell JW: Regulation of cardiac L-type calcium channels by protein kinase A and protein kinase C. Circ Res 2000, 87(12):1095-1102.

51. Katz A, Wu D, Simon Ml: Subunits beta gamma of heterotrimeric $G$ protein activate beta 2 isoform of phospholipase C. Nature 1992, 360(6405):686-689

52. Hein P, Frank M, Hoffmann C, Lohse MJ, Bunemann M: Dynamics of receptor/G protein coupling in living cells. EMBO J 2005, 24(23):4106-4114.

53. Mukhopadhyay S, Ross EM: Rapid GTP binding and hydrolysis by G(q) promoted by receptor and GTPase-activating proteins. Proc Natl Acad Sci USA 1999, 96(17):9539-9544.

54. Bruce C, Weatherstone R, Seaton A, Taylor WH: Histamine levels in plasma, blood, and urine in severe asthma, and the effect of corticosteroid treatment. Thorax 1976, 31(6):724-729.

55. Lambright DG, Sondek J, Bohm A, Skiba NP, Hamm HE, Sigler PB: The 2.0 A crystal structure of a heterotrimeric $\mathrm{G}$ protein. Nature 1996, 379(6563):311-319
56. Li Y, Sternweis PM, Charnecki S, Smith TF, Gilman AG, Neer EJ, Kozasa T: Sites for Galpha binding on the G protein beta subunit overlap with sites for regulation of phospholipase Cbeta and adenylyl cyclase. J Biol Chem 1998, 273(26):16265-16272.

57. Tesmer VM, Kawano T, Shankaranarayanan A, Kozasa T, Tesmer JJ: Snapshot of activated $\mathrm{G}$ proteins at the membrane: the Galphaq-GRK2Gbetagamma complex. Science 2005, 310(5754):1686-1690.

58. Evanko DS, Thiyagarajan MM, Takida S, Wedegaertner PB: Loss of association between activated Galpha q and Gbetagamma disrupts receptor-dependent and receptor-independent signaling. Cell Signal 2005, 17(10):1218-1228.

59. Chachisvilis M, Zhang YL, Frangos JA: G protein-coupled receptors sense fluid shear stress in endothelial cells. Proc Natl Acad Sci USA 2006, 103(42):15463-15468.

60. Zhang YL, Frangos JA, Chachisvilis M: Mechanical stimulus alters conformation of type 1 parathyroid hormone receptor in bone cells. Am J Physiol Cell Physiol 2009, 296(6):C1391-1399.

61. Yasuda N, Miura S, Akazawa H, Tanaka T, Qin Y, Kiya Y, Imaizumi S, Fujino M, Ito K, Zou Y, et al: Conformational switch of angiotensin II type 1 receptor underlying mechanical stress-induced activation. EMBO Rep 2008, 9(2):179-186

62. Sharif-Naeini R, Folgering $J H$, Bichet $D$, Duprat F, Delmas $P$, Patel $A$, Honore E: Sensing pressure in the cardiovascular system: Gq-coupled mechanoreceptors and TRP channels. J Mol Cell Cardiol 2010, 48(1):83-89.

63. Nickenig G, Strehlow K, Roeling J, Zolk O, Knorr A, Bohm M: Salt induces vascular AT1 receptor overexpression in vitro and in vivo. Hypertension 1998, 31(6):1272-1277.

64. Ruan X, Wagner C, Chatziantoniou C, Kurtz A, Arendshorst WJ: Regulation of angiotensin II receptor AT1 subtypes in renal afferent arterioles during chronic changes in sodium diet. J Clin Invest 1997, 99(5):1072-1081.

65. Nagai T, Yamada S, Tominaga T, Ichikawa M, Miyawaki A: Expanded dynamic range of fluorescent indicators for $\mathrm{Ca}(2+)$ by circularly permuted yellow fluorescent proteins. Proc Natl Acad Sci USA 2004, 101(29):10554-10559.

66. Van Munster EB, Gadella TW Jr: phiFLIM: a new method to avoid aliasing in frequency-domain fluorescence lifetime imaging microscopy. J Microsc 2004, 213(Pt 1):29-38.

67. van Munster EB, Gadella TW Jr: Suppression of photobleaching-induced artifacts in frequency-domain FLIM by permutation of the recording order. Cytometry A 2004, 58(2):185-194.

doi:10.1186/1741-7007-9-32

Cite this article as: Adjobo-Hermans et al:: Real-time visualization of heterotrimeric $\mathrm{G}$ protein $\mathrm{Gq}$ activation in living cells. BMC Biology 2011 9:32.

\section{Submit your next manuscript to BioMed Central and take full advantage of:}

- Convenient online submission

- Thorough peer review

- No space constraints or color figure charges

- Immediate publication on acceptance

- Inclusion in PubMed, CAS, Scopus and Google Scholar

- Research which is freely available for redistribution

Submit your manuscript at www.biomedcentral.com/submit
C Biomed Central 